\title{
Cellulosic fiber based hybrid composites: A comparative investigation into their structurally influencing mechanical properties
}

\author{
V. Vignesh ${ }^{1}$, A. N. Balaji ${ }^{2}$, B. R. M. Rabi ${ }^{1}$, N. Rajini ${ }^{3,}{ }^{*}$, N. Ayrilmis ${ }^{4}$, M. K. V. Karthikeyan ${ }^{5}$, \\ F. Mohammade ${ }^{6}$, Sikiru Oluwarotimi Ismail ${ }^{7}$ \\ ${ }^{1}$ Department of Mechanical Engineering, Sethu Institute of Technology, Kariapatti- 626106, Tamil \\ Nadu, India. \\ ${ }^{2}$ Department of Mechanical Engineering, K.L.N. College of Engineering, Pottapalayam - 630612, \\ Sivagangai District, Tamil Nadu, India. \\ ${ }^{3}$ Department of Mechanical Engineering, Kalasalingam Academy of Research and Education, \\ Krishnankoil, - 626126, Tamil Nadu, India. \\ ${ }^{4}$ Department of Wood Mechanics and Technology, Faculty of Forestry, Istanbul University-Cerrahpasa, \\ Bahcekoy, 34473, Sariyer, Istanbul, Turkey \\ ${ }^{5}$ Department of Mechanical Engineering, K.L.N. College of Information Technology, Pottapalayam - \\ 630612, Sivagangai District, Tamil Nadu, India. \\ ${ }^{6}$ Department of Chemistry, College of Science, King Saud University, Riyadh, 11451, Kingdom of \\ Saudi Arabia. \\ ${ }^{7}$ Department of Engineering, Center for Engineering Research, School of Physics, Engineering and \\ Computer Science, University of Hertfordshire, Hatfield, AL10 9AB, England, United Kingdom.
}

*Corresponding author: N. Rajini, E-mail: rajiniklu@gmail.com, Tel.: +919942139392; Fax: $+914563289042$

\begin{abstract}
This paper focuses on hybrid and twisted hybrid Indian mallow/roselle cellulosic fiber yarn mat reinforced polyester composites and effects of their wood sawdust filler. The composite materials were fabricated using compression molding technique. There were four different combinations of hybrid yarn mat composite samples used, while the twisted hybrids were six. An evaluation of the hybrid and twisted hybrid mechanical properties for the single and double layer cases of the yarn mat was done with and without wood sawdust filler effects. The samples were tested at both warp and weft directions. From the results obtained at warp direction, it was observed that for the hybrid double layer case, longitudinal yarn mat with
\end{abstract}


wood sawdust (filler) composite sample exhibited better tensile, impact and flexural strength properties in comparison with other related composites of hybrid type reported in literature. Moreover, the modified twisted hybrid double layer composites with longitudinal yarn mat and wood sawdust filler sample recorded significantly greater improvement on the mechanical properties at warp direction, when compared with the hybrid double layer longitudinal yarn mat composites with wood sawdust filler and other reported similar hybrid composite materials. Scanning electron microscopy (SEM) technique was utilized to evaluate morphological internal damage (cracks) and fractured surfaces of the various tested composite samples. Based on their mechanical performances and for further practical evidence, these two types of eco-composites were used to effectively fabricate tri-wheeler auto-wheel hubs and ceiling fan blades, as applicable to automobile and electronics industries, respectively.

Keywords: Hybrid fiber, twisted hybrid fiber, wood sawdust filler, mechanical properties, scanning electron microscopy.

\section{Introduction}

Nowadays, interest on the use of hybrid natural fibers to reinforce polyester composites and produce a low-cost and environmentally friendly biocomposites is growing. The hybrid natural fibers are strain compatible, as a reason for their selection in hybridizing and reinforcing polyester matrices for the development of high performance and cost-effective composites. The fibers contain high cellulose and low micro fibrillary angle. These properties support high tensile strengths, thus accounting for an easy and better transfer of stress from matrix to fiber in reinforced composites of natural fibers. Furthermore, the extension at the breakpoint of the two fibers can be compared and there is a transfer of stress between the two fibers without matrix failure. Therefore, natural fibers are chosen to hybridize and combine the properties of the two or more fibers to achieve preferable outstanding properties in the hybrid composites. Therefore, the natural fibers are now reinforcement alternatives for the formation of improved fiber reinforced polymer (FRP) composites. They attract researchers, engineers, scientists and professionals across the globe. Moving forward, the extensive interest on this fiber can be attributed to the superiority of their properties. These include low 
weight, specific strength (high), low cost, non-abrasive, mechanical behavior (fairly good), bio-degradable and eco-friendly.

Several researchers have started considering the importance of global need of natural fibers. Consequently, they have studied the performance of hybrid composites, considering the applicability of cellulosic fibers. Many hybrid class of composites have exhibited magnificent properties, while fiber is combined with their counterpart or another reinforcements(s). The following context described the various hybrid composites and their properties, as studied. In that view, Sanjay et al. [1] conducted a study on mechanical behavior of natural-glass fiber reinforced polymer and their hybrid composites. Their results indicated that the glass fiber reinforced polymers hybridized with natural fibers, such as hemp, bamboo, banana, coir, cotton, hemp, pineapple, abaca, jute and sisal possesses an increased product efficiency in both engineering and technology (manufacturing) sectors.

Jacob et al. [2] studied the mechanical behaviors of hybrid sisal/oil palm fiber composite, reinforced by using natural rubber and chopped oil palm and sisal fibers to various lengths. Increasing the natural fiber concentration caused reduction of tear and tensile strengths with an increase in the composite modulus. The alkali treated fiber reinforced composite produced a property, when juxtaposed with the untreated fiber counterpart. Mechanical property variations of hybrid polyester composites of sisal and roselle fibers at both wet and dry conditions were evaluated in the study conducted by Athijayamani et al. [3]. These properties included impact, flexural and tensile strengths. The length and fiber content of the roselle and sisal fibers were increased and observed an increase in both composite flexural as well as tensile strengths, but a decrease in both when moisture content of the environment increased. With fiber composites of $30 \mathrm{wt} \%$ content and $150 \mathrm{~mm}$ length, they observed a reduction percentage for the flexural and tensile strengths was maximum. With respect to the impact strength, $20 \mathrm{wt} \%$ and $150 \mathrm{~mm}$ of composites under wet conditions yielded better results in comparison with the dry conditions. Short bananas with random orientation and sisal hybrid fiber reinforced polyester composites were studied by Idicula et al. [4]. These samples were fabricated at different fiber loadings from volume fraction of 0.20 to 0.50 . By increasing fiber loading, the flexural, tensile and impact behaviors also increased with an improved performance, as recorded with the composite of volume fraction of 0.40 . Higher impact and flexural properties were reflected in bilayer composites when compared with theoretical predictions. Also, study to evaluate matrix-fiber interactions was reported using scanning electron microscopy (SEM). Athijayamani et al. [5] studied hybrid natural fibers reinforced 
polyester with respect to their mechanical behaviors by varying the weight $\%$ and fiber lengths. The results revealed that with $15 \mathrm{~cm}$ length of fiber and $30 \%$ fiber weight, both tensile as well as flexural strengths increased. Nevertheless, the strength of impact reduced when fiber content as well as fiber length increased.

In addition, Jawaid et al. [6] reported on the tensile behaviors of oil palm/jute fiber reinforced polymer hybrid composites. The oil palm empty fruit bunches (EFB) were used for skin material, while the jute formed the core of the sample in line with the relative ratio (weight) of 4:1 for oil palm EFB/Jute. Different patterns of layers were used to optimize the fiber loading. With skin being jute and core material being oil palm EFB, slightly higher tensile properties were reported for the composites. Various tensile surfaces of the fractured composites were studied by SEM analysis. Furthermore, Venkateswaran et al. [7] investigated hybrid mixture rule for composite of hybrid natural fiber with short random orientation, thereby predicted their tensile properties. Ratios of 40:0, 30:10, 20:20, 10:30 and 0:40 were used for the hybrid composites, prepared from banana/sisal fibers. Slightly higher tensile strength and modulus were reported for the natural FRP hybrid composites with randomly short orientation than the values from experiments. Dhakal et al. [8] studied fiber treatment and glass fiber hybridization with respect to their influence on thermal degradation of hemp/unsaturated polyester composites (HFRUP) and their surface energy characteristics, using thermo-gravimetric analyzer (TGA). A comparison between HFRUP composites and the unreinforced UP, $\mathrm{NaOH}$ treated hemp and glass fiber hybridized hemp/UP composites was carried out. The results from the TGA tests showed that all the samples experienced weight losses between temperatures of 200 and $415^{\circ} \mathrm{C}$.

Júnior et al. [9] conducted a study on the thermal, mechanical and dynamic mechanical analyses of hybrid intra laminate glass/caraua composites with 20,30 and 40 vol. \% of total fiber volume fractions. Thermal analysis and mechanical properties showed higher impact strength, hardness and thermal stability with an addition of glass fiber. Hybridization of the $30 \%$ caraua fiber composite to replace the glass fiber showed similar characteristics with a better result when compared with the pure glass composite. Ramnath et al. [10] studied abaca-jute-glass reinforced epoxy fiber composites with respect to their mechanical responses, reported an improved tensile strength with the abaca composites, better than the jute composite as it recorded the highest value of $16 \mathrm{~J}$ for both flexural and impact strengths, when compared with the jute composite. Ramesh et al. [11] also investigated the mechanical responses of sisal-jute-glass fiber reinforced polyester composites and found out that the jute 
composite sample exhibited a good tensile strength as high as $229.54 \mathrm{MPa}$. The composite sample of hybridized sisal and jute was capable of exhibiting highest flexural strength with $14.2 \mathrm{~mm}$ in displacement under a load of $3.00 \mathrm{kN}$. The sisal fiber composite yielded highest impact strength up to $18.67 \mathrm{~J}$.

Moreover, Gujjala et al. [12] investigated into the mechanical responses of woven juteglass FRP epoxy hybrid composite. These properties included flexural, tensile and interlaminar shear behaviors. A maximal flexural strength in L3 (jute/glass/jute/glass) after glass fiber composites was reported. The L5 hybrid composites produced $75 \%$ glass fiber composites strength. Similarly, Vinayagamoorthy et al [13] worked on the mechanical performance of vetiveria zizanioides/jute/glass fiber reinforced hybrid polymeric composites. Nine composite samples of constant resin content with varying natural and glass fiber proportions were prepared and tested for flexural, compressive, impact and tensile strengths. The results depicted that the mechanical behaviors of the hybrid composite samples were substantially improved by adding chemically treated vetiveria fiber.

Furthermore, Zuhudi et al. [14] studied how hybridization influenced the thermal, flammability, impact and dynamic mechanical behaviors of hybrid composites of bambooglass polypropylene. The TGA results showed more thermal stability for hybrid composites before commencing degradation at $275{ }^{\circ} \mathrm{C}$ and attaining full degradation at $400{ }^{\circ} \mathrm{C}$. Comparing Charpy impact strengths of $530.9 \mathrm{~J} / \mathrm{m}$ for composites of bamboo-polypropylene, the hybrid composites exhibited an increased value of $1129.2 \mathrm{~J} / \mathrm{m}$. Parandaman et al. [15] investigated the mechanical responses of sugarcane bagasse and banana FRP composite for the purpose of eco-friendliness and in comparison with synthetic fibers. The composite result showed that the chopped fiber reinforcement possessed improved mechanical response when compared with being linearly reinforced. The interfacial bonding was better in chopped fiber reinforcement than the continuous fiber reinforcement, as the chopped case exhibited better mechanical behaviors than the continuous sample. Panneerdhass et al. [16] investigated a research on mechanical response of hybrid composites of luffa fiber and groundnut reinforced epoxy polymer. The results ranged between 10.35 and 19.31 MPa for the tensile, 26.66 to 52.22 $\mathrm{MPa}$ for the compression and 35.75 to $58.95 \mathrm{MPa}$ for flexural strengths, while the impact energy ranged between 0.6 and $1.3 \mathrm{~J}$, subject to fiber volume fraction. $40 \%$ of volume fiber fraction yielded the optimum mechanical response, as recorded by the treated fiber composite. SEM analysis was also performed on the composite materials. 
Karahan et al. [17] studied the tensile mechanical behaviors of hybrid FRP composites, fabricated from natural and natural/synthetic woven fabric in comparison with those of the 3 $\mathrm{K}$ carbon composites (woven fabric). Changes in temperature enormously affected the mechanical behavior of the natural FRP composites, though significantly less than that of composites of carbon fiber. This was due to the impacts of hybridized jute and carbon fibers in the composite material, which consequently enhanced their mechanical responses. Alavudeen et al. [18] worked on banana/kenaf fiber FRP hybrid composites in terms of their mechanical properties and considered the random orientation as well as the woven fabric effects. They found out an increased mechanical strength in the plain woven hybrid composites, when compared with composites that were randomly oriented. Palanikumar et al. [19] investigated the mechanical response of green hybrid sisal as well as glass fiber FRP composites, experimentally. The hybrid composites showed significant improvements with respect to their flexural, impact and tensile behaviors. In addition, the composites supported reduction in the environmental effects. Analysis was done for the broken surface internal structure, fibers delamination and failure morphology, using the SEM technique. Arpitha et al. [20] studied the effect of hybridizing woven fabric sisal/glass/epoxy/filler based reinforced composites. Five composites of different laminates were prepared, using hand layup in combination with the method of vacuum bagging with respect to laminate sequences. The flexural properties were enhanced by the filler effect. Composite failures occurred mainly because of the poor bonding in the fabrics-matrix interface, as pull-out of fabrics and fracture were observed in the matrix and fabrics, respectively.

More also, Chaudhary et al. [21] investigated into the structural applications, morphological and mechanical characterization of hybrid composites of developed jute/hemp/flax FRP. Highest values of $58.59 \mathrm{MPa}, 10.19 \mathrm{~kJ} / \mathrm{m}^{2}$ and $1.88 \mathrm{GPa}$ were respectively obtained for the tensile, impact and modulus strengths of the hybrid composites of the jute/hemp/flax/epoxy. The highest flexural strength of the jute/hemp/epoxy hybrid composite was 86.6 MPa. Udayakumar et al. [22] studied the modified coconut shell powder (CSP) and coir fiber (CF), using silane and alkali treatments on the reinforcements of the vinyl ester (VE) composites. The result was better in terms of hardness as well as tensile properties for the composites of CFs as well as the CSP/VE with surface treatment. With reinforcement modification using alkali as well as silane, there was an enhanced mechanical response of the VE hybrid composite. 
Additionally, Sathishkumar et al. [23] studied how fiber orientation as well as stacking sequence could affect the thermal and mechanical attributes of banana-kenaf FRP hybrid composite. The process of hand layup was employed to fabricate the composite with various fiber orientations, containing five various proportions of banana-kenaf fibers. The results depicted better properties of the hybrid composite at $45^{\circ}$ fiber inclination than the others. They also carried out an analysis of failure morphology, using SEM as well as the tested sample internal structures. Bharathiraja et al. [24] experimentally conducted a study on rice husk as well as hybrid composites of red mud coir-polyester (bio-particulate) with respect to their mechanical behaviors. With $30 \mathrm{~mm}$ length of fiber and $15 \%$, the maximum flexural, impact and ultimate tensile strengths were observed.

From the aforementioned and extensively reported literature, it was evident that there was a great demand and search for a new natural fiber for composite reinforcement to improve its specific properties without causing environmental hazards. Therefore, effectively utilizing natural fibers of different sorts as reinforcements to improve composites of polymer matrix is a continuous quest. Survey made under the randomly oriented natural fibers, unidirectional natural fiber and secondary raw filler underscored the role of mat structure towards adhesion enhancement between hydrophilic fibers and hydrophobic matrix. As clearly evident from the studies previously reported, hybrid mat offered a simple as well as the most efficient method of fiber properties improvement, as often use in nearly all natural fiber types. With effective utilization, outstanding reinforcement of various matrices is achievable with better mechanical performances of polymer composites. Thus, in this experimental investigation, an attempt was successfully made to introduce Indian mallow fiber/reselle fiber as a main reinforcement and wood sawdust filler as a material for secondarily reinforcing polyester matrix composites. Furthermore, the mechanical responses of the hybrid and twisted hybrid Indian mallow/roselle fiber yarn mat composites; with and without wood sawdust filler reinforced polyester have been comprehensively investigated in this study.

\section{Experimental details}

\subsection{Materials}

Indian mallow plants were obtained from Madurai, Tamil Nadu, India. The stem of the plant produced the fiber (Fig. 1(a)), as a primary reinforcement of the biocomposite. The 
plant survives all climatic conditions and is easy to cultivate. Therefore, it grows highly gregariously in dry, shady waste locations and ditches. For these reasons, it can be found commonly in India [25]. The mechanical and physicochemical properties of Indian mallow fibers in comparison with other similar natural fibers are presented in Table 1. Fig. 1(b) shows roselle fiber, which has been extracted from the stem of roselle plant that was collected from Aduthurai, Tamil Nadu, India. The sawdust procured for the experiment was obtained from the teak tree saw mills at Madurai, Tamil Nadu, India, as depicted in Fig. 1(c). The matrix used was unsaturated isothallipic polyester resin. The methyl ethyl ketone peroxide (MEKP) and cobalt naphthanate were respectively used as catalyst and accelerator. Prasana Resins (P) Ltd, Madurai, Tamil Nadu, India, supplied the accelerator, catalyst and unsaturated isothallipic polyester resin matrix [26].

\subsection{Production of composites}

Bunches of Indian mallow and roselle fibers were converted into their respective yarn forms; simple roselle yarn, Indian mallow yarn and twisted hybrid Indian mallow/roselle yarn bundle, as shown in Figs. 2(a), (b) and (c), respectively. Furthermore, the individual yarns and bundles were converted into their respective yarn mats (Figs. 3a, b and c), with the aid of a weaving machine. This was done to strengthen their mechanical properties. The reinforcement materials used for composite fabrication were roselle fiber yarn mat and Indian mallow. The manufacturing method used was compression molding (SANTEC Hydraulic Compression Moulding machine) with weight capacity of $300 \mathrm{~kg}$ [42-44]. The woven Indian mallow fiber yarn mats layers, both single and double, were placed in a $200 \mathrm{~mm} \times 200 \mathrm{~mm} \times$ $3 \mathrm{~mm}$ mold in both transverse and longitudinal orientations. The mold was used to make the samples without filler at this stage. Then, resin and curing agents were mixed and poured into the cavity of the mold. With sawdust filler addition at $15 \mathrm{wt} \%$, the aforestated procedure was repeated, by pouring resin into the mold cavity for single and double layers of the woven Indian mallow fiber yarn mats. The pressure was kept constant at $100 \mathrm{kPa}$, while the mold remained closed. For an uninterrupted period of $24 \mathrm{~h}$ in a room temperature, the composites were left to cure. Care was extremely taken to ensure plate of Indian mallow fiber yarn mat composite made was design and set-up to support uniformly distribution of the composites. Both Figs. 4(a) and (b) show the four different hybrid Indian mallow/roselle fiber yarn mat and six various combinations of twisted Indian mallow/roselle fiber yarn mat polyester composite plates, respectively. Table 2 presents the designations used to represent the various 
hybrid and twisted hybrid combinations for Indian mallow fiber yarn mats, containing wood sawdust filler reinforced polyester composite samples.

\subsection{Mechanical tests}

\subsubsection{Tensile test}

Tensile test was carried out on a digital universal testing machine (Tinius Olsen H50K) at $1 \mathrm{~mm} / \mathrm{min}$ speed of cross head in accordance with ASTM standards. From the composite plates, samples were cut into dimensions of $165 \mathrm{~mm}, 10 \mathrm{~mm}$ and $3 \mathrm{~mm}$, representing length, width and thickness respectively, following ASTM D 638-10 standards for measuring tensile properties. A minimum of five samples were tested and the average value was reported. $[26,44]$.

\subsubsection{Flexural test}

On a universal digital testing machine (Tinius Olsen H50K), 3-point flexural test was carried out at $2 \mathrm{~mm} / \mathrm{min}$ speed of cross head in accordance with ASTM D790-10 standard for measuring flexural behaviors of composite materials. The sample specifications used for this test were lengths, width and thickness of $127 \mathrm{~mm}, 13 \mathrm{~mm}$ and $3 \mathrm{~mm}$. A minimum of five samples were tested and the average value was reported $[26,42]$.

\subsubsection{Impact test}

The sample impact strengths were obtained from a Tinius Olsen (Model: 104) Izod digital impact testing machine in accordance with ASTM D256-10 standard. The length, width and thickness of sample dimension used were $65 \mathrm{~mm}, 13 \mathrm{~mm}$ and $3 \mathrm{~mm}$. A minimum of five samples were tested and the average value was reported. [26,42-44].

\subsubsection{Scanning electron microscope analysis}

After carrying out the tensile, flexural and impact tests, SEM technique was used to examine the fractured surfaces of the mechanically tested composite samples and a detailed morphological studies at various magnifications have been conducted. Fractured sample images were taken at a voltage of 10-15 kV (SEM Model No: FEI-Quanta 250) $[27,43]$. 


\section{Results and discussion}

\subsection{Tensile properties}

The tensile responses of the yarn mat of hybrid Indian mallow/roselle fiber reinforced polyester composites were analyzed, with and without the presence of sawdust filler after they have been loaded or tested at both warp and weft directions. The tensile specimen during tensile test is shown in Fig.5. The woven fiber composite strength depended on fiber direction, fiber orientation, weave style as well as fiber-matrix bonding [18]. As observed, tensile strength of the HIRDLLF composites with sample loading at warp direction was higher than the HIRDLL (without wood sawdust filler) composites. This depicted property improvement, due to the presence of sawdust filler in HIRDLLF sample. However, the difference between increase in tensile strength of HIRDLLF compared with HIRDLL sample was higher than that of HIRDLBF over HIRDLB composite samples. Similarly, the two layers were arranged in both transverse and longitudinal direction during fabrication. The longitudinal fabricated composites exhibited a higher tensile strength than the corresponding transverse direction counterparts, regardless of the fiber type used for polyester matrix reinforcement. The observed better tensile properties can be attributed to the uniformly distributed stress and tensile load transfer on longitudinal direction.

Moving forward, the HIRDLLF composites exhibited highest tensile strength of $95 \mathrm{MPa}$, tensile modulus of $3.33 \mathrm{GPa}$ and $2.85 \%$ elongation. A $32 \%$ tensile strength increase was observed over HIRDLL composites, $47 \%$ and $43 \%$ increase over the HIRDLB and HIRDLBF composite samples, respectively. The stronger and stiffer hybrid Indian mallow and roselle fibers were longitudinally oriented, which could allow greater capacity for stress uptake as well as higher mechanical strength. The composites with maximum mechanical strength were identified as those of the fabricated plain weave hybrid. The tensile properties of the four different hybrid yarn mat composites at warp direction are shown in Fig. 6(a). The twisted hybrid Indian mallow/roselle fiber yarn mat reinforced polyester composites with and without filler composites sample at both warp and weft directions were analyzed to investigate improvements in their mechanical properties. Tensile properties of six various twisted hybrid yarn mat composites with and without the sawdust filler at warp direction are shown in Fig. 6(b). It was observed, from Fig. 5, that the single layer twisted hybrid composites clearly showed a maximum tensile strength in THIRFSLF composite when compared with other THIRFSL composite samples. The tensile modulus of THIRFSLF composite was better when there was no filler present in the composite. The elongation of THIRFSL with and without 
filler composite varied from 2.35 to $3.39 \%$. in double layer twisted hybrid composites, the THIRDLLF composite samples withstood up to $136 \mathrm{MPa}$, followed by THIRDLL of 101 MPa, THIRDLB of $54 \mathrm{MPa}$ and THIRDLBF composites of $58 \mathrm{MPa}$. The greatest tensile modulus of THIRDLLF composite was $4.87 \mathrm{GPa}$, when compared to THIRDLL, THIRDLB and THIRDLBF composites. The elongation of THIRDLLF, THIRDLL, THIRDLBF and THIRDLB composites were 4.87, 3.68, 2.93 and 2.57\%, respectively. Also, the tensile strength of the hybrid and twisted hybrid Indian mallow/roselle fiber yarn mat reinforced polyester composites were compared with various natural and synthetic fiber reinforced polyester composites, as shown in Table 3. Evidently, it was comparatively higher than all the listed similar composites.

At weft direction, the tensile strengths of hybrid and twisted hybrid Indian mallow/roselle fiber yarn mat reinforced polyester composites with and without filler composite samples are respectively shown in Fig. 7(a) and Fig. 7(b). The tensile strengths of the HIRDLL, HIRLLF, HIRDLB and HIRDLBF reinforced polyester composites varied from 22 to $59 \mathrm{MPa}$, respectively. The tensile strengths of the THIRFSL, THIRFSLF, THIRDLL, THIRDLLF, THIRDLB and THIRDLBF reinforced polyester composites were obtained at 12, 18, 24, 32, 50 and $56 \mathrm{MPa}$, respectively. From the analysis, it was evident that the HIRDLBF and THIRDLBF composites maintained better tensile strengths, when compared with the other composite samples. Conversely, the tensile strength results were lower in the hybrid Indian mallow/roselle fiber yarn mat reinforced polyester composite, when tested at weft direction. The composite sample tested at warp direction exhibited higher values than the counterparts that were tested at weft direction, due to less load transfer between the yarn fiber and the matrix at weft direction.

\subsection{Flexural properties}

With THIRDLLF composite at warp direction, flexural strength was observed to be higher with a value of $330 \mathrm{MPa}$. With the single layer, THIRFSLF composite sample recorded flexural strength better than THIRFSL composite. This can be attributed to the dense structure of wood sawdust filler, predominating the porous structure of the hybrid fibers. The hybrid effect in weaving patterns of both fiber yarns at both weft and warp directions is capable of creating interlocks in the structure. As for the double layer, the flexural properties of the four different hybrid yarn mat composites at warp direction are shown in Fig. 8(a), while Fig. 8(b) shows the six different twisted hybrid yarn mat 
composites with and without sawdust filler, at warp direction. The hybrid yarn mat composite, under an increased flexural load from 93 to $198 \mathrm{~N}$ exhibited an increased flexural strength from 119 to $292 \mathrm{MPa}$. Higher flexural strength was observed at warp direction for HIRDLLF composite samples. It was nearly $13 \%, 59.2 \%$ and $65.4 \%$ more than that of HIRDLL, HIRDBLF and HIRDBL composite samples, respectively.

Moreover, in twisted hybrid yarn mat composite, the flexural load varied from 107 to $258 \mathrm{~N}$ and the flexural strength for THIRDLLF composite was higher by comparison than that of HIRDLL, HIRDLLF, HIRDBL, HIRDBLF, THIRFSL, THIRFSLF, THIRDLL, THIRDLB and THIRDLBF composite samples. This can be traced to fiber yarn extension constraints along both longitudinal and transverse directions, which resulted to fibers whose capacity for bending load was higher. Incorporating the hybrid fiber led to a higher capacity to withstand the compressive strength as well as provided more resistance to shear force [18].

At weft direction, the flexural strengths of different composite samples of hybrid and twisted hybrid Indian mallow/roselle fiber yarn mat reinforced polyester composites with and without filler tested are shown in Figs. 9(a) and (b), respectively. From Fig. 8, the flexural strength was observed at $120 \mathrm{MPa}$ in THIRDLBF composite samples, at weft direction. There was an improved enhancement in their mechanical properties compared to other composite samples, with approximately $76,76,70.8,66,61,60,13,12.5$ and $2.5 \%$ higher than that of THIRFSL, THIRDLB, THIRFSLF, THIRDLL, HIRDLL, THIRDLLF, HIRDLB, HIRDLLF and HIRDLBF reinforced polyester composite samples, respectively. The comparison of flexural strengths with various extant hybrid (natural and synthetic) fiber reinforced polyester and other related composites is shown in Table 4, with the best or highest results obtained in this present study.

\subsection{Impact properties}

The variations in the impact strengths of hybrid and twisted hybrid yarn mat reinforced polyester composites are respectively shown in Figs. 10(a) and (b). From the hybrid composite sample, a higher impact strength was obtained at $190 \mathrm{~kJ} / \mathrm{m}^{2}$ for HIRDLLF reinforced polyester composite samples, when compared with the other composite counterparts. It was nearly 1.18, 1.86 and 2.5 times higher compared to HIRDLL, HIRDLBF and HIRDLB composite samples, respectively. 
In addition, from the twisted hybrid composites, the THIRDLLF reinforced polyester composite sample exhibited a high impact strength of $225 \mathrm{~kJ} / \mathrm{m}^{2}$, when compared with the THIRFSL, THIRFSLF, THIRDLL, THIRDLLF, THIRDLB and THIRDLBF composite samples. This value was nearly $4.09,2.81,2.04,1.5$ and 1.10 times higher than that of THIRFSL, THIRFSLF, THIRDLB, THIRDLBF and THIRDLL composite samples, respectively. This can be attributed to the influence of fiber twisting technique; as it supported higher strength and exchanged the properties of two natural fibers between the Indian mallow fiber/roselle fiber and matrix of the hybrid natural fiber. It further aided a high capacity for absorption with uniformly distributed impact energy.

Table 5 shows the comparison of impact strengths of the various hybrid natural and synthetic fiber reinforced polyester composite samples. The impact strengths of the twisted hybrid yarn mat reinforced polyester composite samples, at weft direction, are shown in Fig. 11(a). From the results obtained, the impact strengths of the THIRFSL, THIRFSLF, THIRDLL, THIRDLLF, THIRDLB and THIRDLBF reinforced polyester composite samples were measured at 14, 22, 39, 44, 100 and $120 \mathrm{~kJ} / \mathrm{m}^{2}$, respectively. The THIRDLBF composite sample showed a better impact strength than that of THIRFSL, THIRFSLF, THIRDLL, THIRDLLF and THIRDLB/polyester composite sample by 88, 81, 67, 63 and 16 increases, respectively.

Also, the impact strengths of the hybrid yarn mat reinforced polyester composite samples for weft direction are as shown in Fig. 11(b). The hybrid Indian mallow/roselle fiber yarn mat reinforced polyester composite samples had impact strength variation from 35 to $84 \mathrm{~kJ} / \mathrm{m}^{2}$. Based on the results obtained, the HIRDLBF composite sample exhibited a better impact strength than that of HIRDLL, HIRDLLF and HIRDLB composite samples, by $58 \%, 50 \%$ and $11.9 \%$, respectively.

\subsection{SEM analysis}

The SEM analysis presented in Figs. 12(a) and (b) shows a few fiber tears and matrix breakage in the hybrid composite. There were presence of fillers and fiber break-out in the hybrid composites, as depicted in Figs. 13(a) and (b). In addition, the SEM micrographs in Figs. 14(a) and (b) indicate clearly the presence of matrix fractures on the twisted hybrid mallow/roselle fiber yarn mat composite samples. Furthermore, fiber bending, breakage and 
pull-out were scarcely observed from the twisted composites, as shown through the SEM analysis conducted, as depicted in Figs. 15(a)-(d).

\section{Applications}

An automobile four-wheeler side mirrors were fabricated with the twisted hybrid composites, as top and bottom views are respectively shown in Figs. 16(a) and (b). In addition, tri-wheeler auto-wheel hub and ceiling fan blade were similarly fabricated, using the twisted hybrid composite materials, as depicted in Figs. 17(a) and (b), respectively. From the analysis obtained, we can conclude that the developed novel hybrid composites can be very useful and vital in automobile and electronics sectors. The hybrid natural fiber yarn mat material can be an alternative, having low cost with eco-friendliness, when compared with the extant metallic, alloy, synthetic (carbon and glass) FRP composite products.

\section{Conclusions}

The hybrid and twisted hybrid Indian mallow/roselle fiber yarn mat reinforced polyester composites have been developed. The effects of wood sawdust filler on the composites were also investigated. Several tests on flexural, tensile and impact strengths as mechanical characteristics of the composite samples were carried out at both warp and weft directions and the results obtained were extensively analyzed. Therefore, the subsequent concluding remarks were drawn.

- The HIRDLLF composite sample, tested at warp direction exhibited better enhancements in terms of higher tensile, impact and flexural strengths of $95 \mathrm{MPa}, 190 \mathrm{~kJ} / \mathrm{m}^{2}$ and 292 $\mathrm{MPa}$, respectively, when compared with other counterparts: HIRDLL, HIRDLB and HIRDLBF composite samples.

- The HIRDLBF composite samples recorded an optimum/best improvement on the mechanical properties, at weft direction and when compared with other composite samples.

- Furthermore, the mechanical properties of the THIRFSLF samples were significantly increased than their corresponding THIRFSL, when the composite samples were loaded/tested at warp direction.

- Considering the double layer reinforcement, the THIRDLLF sample showed higher results of impact, tensile and flexural strengths with values of $225 \mathrm{~kJ} / \mathrm{m}^{2}, 136 \mathrm{MPa}$ and 
$330 \mathrm{MPa}$ respectively, than other composite counterparts, when the samples were loaded at warp direction.

- Innovatively, an automobile four-wheeler side mirrors, tri-wheeler auto-wheel hubs and ceiling fan blade (home appliance) were successfully fabricated to establish the practical engineering applications of the optimum samples, using the twisted hybrid composites.

\section{Acknowledgments}

The members of the research team sincerely appreciate all the supports provided by the Managements of Sethu Institute of Technology and K.L.N. Colleges of Engineering, Tamil Nadu, India.

\section{References}

[1] M.R. Sanjay, G. R. Arpitha, B. Yogesha. Study on mechanical properties of naturalglass fiber reinforced polymer hybrid composites: A review. Materials Today: Proceedings, 2:2959-2967,2015.

[2] M. Jacob, S. Thomas, K.T. Varughese. Mechanical properties of sisal/oil palm hybrid fiber reinforced natural rubber composites. Composites Science and Technology, 64(7):955-965,2004.

[3] A. Athijayamani, M. Thiruchitrambalam, U. Natarajan, B. Pazhanivel. Effect of moisture absorption on the mechanical properties of randomly oriented natural fibers/polyester hybrid composite. Materials Science and Engineering A,517(1):344353,2009 .

[4] M. Idicula, K. Joseph, S. Thomas. Mechanical performance of short banana/sisal hybrid fiber reinforced polyester composites. Journal of Reinforced Plastics and Composites, 29(1):12-29,2010.

[5] A. Athijayamani, M. Thiruchitrambalam, V. Manikandan, B. Pazhanivel. Mechanical properties of natural fibers reinforced polyester hybrid composite. International Journal of Plastics Technology, 14(1):104-116,2010.

[6] M. Jawaid, H.A. Khalil, A.A. Bakar, P.N. Khanam. Chemical resistance, void content and tensile properties of oil palm/jute fiber reinforced polymer hybrid composites. Materials and Design, 32(2):1014-1019,2011.

[7] N. Venkateshwaran, A. Elayaperumal, G.K. Sathiya. Prediction of tensile properties of hybrid-natural fiber composites. Composites Part B: Engineering, 43(2):793-796,2012. 
[8] H.N. Dhakal, Z.Y. Zhang, N. Bennett. Influence of fiber treatment and glass fiber hybridisation on thermal degradation and surface energy characteristics of hemp/unsaturated polyester composites. Composites Part B: Engineering, 43(7):27572761,2012 .

[9] J.H.S.A. Júnior, H.L.O. Júnior, S.C. Amico, F.D.R. Amado. Study of hybrid intralaminar tecuraua/ glass composites. Materials and Design, 42:111-117,2012.

[10] B.V. Ramnath, S.J. Kokan, R.N. Raja, R. Sathyanarayanan, C. Elanchezhian, A.R. Prasad, V.M. Manickavasagam. Evaluation of mechanical properties of abaca-juteglass fiber reinforced epoxy composite. Materials and Design, 51:357-366,2013.

[11] M. Ramesh, K. Palanikumar, K.H. Reddy. Mechanical property evaluation of sisaljute-glass fiber reinforced polyester composites. Composites Part B: Engineering, 48(1):1-9,2013.

[12] R. Gujjala, S. Ojha, S.K. Acharya, S.K. Pal. Mechanical properties of woven jute-glass hybrid-reinforced epoxy composite. Journal of Composite Materials, 48(28):34453455,2014 .

[13] R. Vinayagamoorthy, N. Rajeswari. Mechanical performance studies on vetiveria zizanioides/jute/glass fiber-reinforced hybrid polymeric composites. Journal of Reinforced Plastics and Composites, 33(1):81-92,2014.

[14] N.Z. MZuhudi, R.J. Lin, K. Jayaraman. Flammability, thermal and dynamic mechanical properties of bamboo-glass hybrid composites. Journal of Thermoplastic Composite Materials, 29(9):1210-1228,2016.

[15] P. Parandaman, M. Jayaraman. Mechanical behaviour of sugarcane bagasse and banana fibers reinforced composite. Applied Mechanics and Materials, 766:104-109,2015.

[16] R. Panneerdhass, A. Gnanavelbabu, K. Rajkumar. Mechanical properties of luffa fiber and groundnut reinforced epoxy polymer hybrid composites. Procedia Engineering, 97:2042-2051,2014.

[17] M. Karahan, N. Karahan. Investigation of the tensile properties of natural and natural/synthetic hybrid fiber woven fabric composites. Journal of Reinforced Plastics and Composites, 34(10):795-806,2014.

[18] A.Alavudeen, N. Rajini, S. Karthikeyan, M. Thiruchitrambalam, N. Venkateshwaren. Mechanical properties of banana/kenaf fiber-reinforced hybrid polyester composites: Effect of woven fabric and random orientation. Materials and Design, 66:246257,2015 . 
[19] K. Palanikumar, M. Ramesh, K.H. Reddy. Experimental investigation on the mechanical properties of green hybrid sisal and glass fiber reinforced polymer composites. Journal of Natural Fibers, 13(3):321-331,2016.

[20] G.R. Arpitha, M.R. Sanjay, P. Senthamaraikannan, C. Barile, B. Yogesha. Hybridization effect of sisal/glass/epoxy/filler based woven fabric reinforced composites. Experimental Techniques, 41(6):577-584,2017.

[21] V. Chaudhary, P.K. Bajpai, S. Maheshwari. Studies on mechanical and morphological characterization of developed jute/hemp/flax reinforced hybrid composites for structural applications, Journal of Natural Fibers, 15(1):80-97,2018.

[22] M. Uthayakumar, V. Manikandan, N. Rajini, P. Jeyaraj. Influence of redmud on the mechanical, damping and chemical resistance properties of banana/polyester hybrid composites. Materials and Design, 64:270-279,2014.

[23] T.P. Sathishkumar, J. Naveen, P. Navaneethakrishnan, S. Satheeshkumar, N. Rajini. Characterization of sisal/cotton fiber woven mat reinforced polymer hybrid composites. Journal of Industrial Textiles, 47(4):429-452,2017.

[24] G. Bharathiraja, S. Jayabal, S. Sathiyamurthy. Mechanical behaviors of rice husk and red mud hybrid bio particulated coir-polyester composites. International Journal of ChemTech Research, 6:3318-3320,2014.

[25] V. Vignesh, A.N. Balaji, M.K.V. Karthikeyan. Effect of wood sawdust filler on the mechanical properties of Indian mallow fiber yarn mat reinforced with polyester composites. International Journal of Polymer Analysis Characterization, 22(7):610$621,2016$.

[26] V. Vignesh, A.N. Balaji, M.K.V. Karthikeyan. Extraction and characterization of new cellulosic fibers from Indian mallow stem - An exploratory investigation. International Journal of Polymer Analysis Characterization, 21(6):504-512,2016.

[27] M.K.V. Karthikeyan, A. N. Balaji, V. Vignesh. Effect of rope mat and random orientation on mechanical and thermal properties of banana ribbon-reinforced polyester composites and its application. International Journal of Polymer Analysis Characterization, 21(4):296-304,2016.

[28] V.S. Sreenivasan, S. Somasundaram, D. Ravindran, V. Manikandan, R. Narayanasamy. Microstructural, physico-chemical and mechanical characterisation of Sansevieria cylindrical fibers-An exploratory investigation. Materials and Design, 32(1):453461,2011 . 
[29] A.V. Prasad, K.M. Rao. Mechanical properties of natural fiber reinforced polyester composites: Jowar, sisal and bamboo. Materials and Design, 32(8):4658- 4663,2011.

[30] B.M, Dabade, G.R. Reddy, S. Rajesham, C. Udhayakiran. Effect of fiber length weight ratio on tensile properties of sunhemp and palmyra fiber reinforced polyester composites. Journal of Reinforced Plastics and Composites, 25(16):1733-1738,2006.

[31] V.A. Prabu, V. Manikandan, R. Venkatesh, P. Vignesh, S. Vignesh, K.S. Sankar, P. Sripathy, E. Subburaj. Influence of redmud filler on Palmyra fruit and Palmyra fiber waste reinforced polyester composite: Hardness, tensile and impact studies. Materials Physics and Mechanics, 24:41-49,2015.

[32] C. UdayaKiran, G.R. Reddy, B.M. Dabade, S. Rajesham. Tensile properties of sun hemp, banana and sisal fiber reinforced polyester composites. Journal of reinforced plastics and composites, 26(10):1043-1050,2007.

[33] M.J. Sharba, Z. Leman, M.T. Sultan, M.R. Ishak, M.A.A. Hanim, Effects of kenaf fiber orientation on mechanical properties and fatigue life of glass/kenaf hybrid composites. BioResources, 11(1):1448-1465,2015.

[34] P. Sathish, R. Kesavan, B.V. Ramnath, C. Vishal. Effect of fiber orientation and stacking sequence on mechanical and thermal characteristics of banana-kenaf hybrid epoxy composite. Silicon, 9(4):577-585,2017.

[35] B.M. Dabade, G.R. Reddy, S. Rajesham, C. Udhayakiran. Effect of fiber length weight ratio on tensile properties of sunhemp and palmyra fiber reinforced polyester composites. Journal of Reinforced Plastics and Composites, 25(16):1733-1738.2006.

[36] S. Mutalikdesai, G. Sujaykumar, A. Raju, C.J. Moses, J. Jose, J. Lakshmanan. Mechanical characterization of epoxy/basalt fiber/flax fiber hybrid composites. American Journal of Materials Science, 7(4):91-94,2017.

[37] V.A. Prabu, S.T. Kumaran, M. Uthayakumar. Influence of redmud particle hybridization in banana/sisal and sisal/glass composites. Particulate Science and Technology, 36(4):402-407,2018.

[38] C. Thiruvasagam, S. Prabagaran, P. Suresh. Study of the mechanical performance and analysis of hybrid natural snake grass-jute-glass fiber strengthened polyester composite. International Journal of Engineering and Technology, 7:78-83,2017.

[39] M. Ramesh, K. Palanikumar, K.H. Reddy. Comparative evaluation on properties of hybrid glass fiber-sisal/jute reinforced epoxy composites. Procedia Engineering, 51:745-750,2013. 
[40] F.H. De Oliveira, A.L. Helfer, S.C. Amico. Mechanical behavior of unidirectional curaua fiber and glass fiber composites. Macromolecular Symposia, 319(1):83-92,2012.

[41] A. Bezazi, A. Belaadi, M. Bourchak, F. Scarpa, K. Boba. Novel extraction techniques, chemical and mechanical characterisation of Agave americana $L$ natural fibers. Composites Part B: Engineering, 66:194-203,2014.

[42] B.Stalin, N. Nagaprasad, V. Vignesh, M. Ravichandran, Nagarajan Rajini, Sikiru Oluwarotimi Ismail, Faruq Mohammad. Evaluation of mechanical, thermal and water absorption behaviors of Polyalthia longifolia seed reinforced vinyl ester composites. Carbohydrate Polymers, 248: 2020.

[43] G.Pitchayya Pillai, P. Manimaran, V. Vignesh. Physico-chemical and Mechanical Properties of Alkali-Treated Red Banana Peduncle Fiber. Journal of Natural Fibers, 1102020.

[44] Stalin, A., S. Mothilal, V. Vignesh, M. R. Sanjay, and Suchart Siengchin. "Mechanical properties of hybrid vetiver/banana fiber mat reinforced vinyl ester composites." Journal of Industrial Textiles, 2020. doi.org/10.1177/1528083720938161.

[45] Manimaran, P., G. Pitchayya Pillai, V. Vignesh, and M. Prithiviraj. "Characterization of natural cellulosic fibers from Nendran Banana Peduncle plants." International Journal of Biological Macromolecules 162:1807-1815, 2020. 